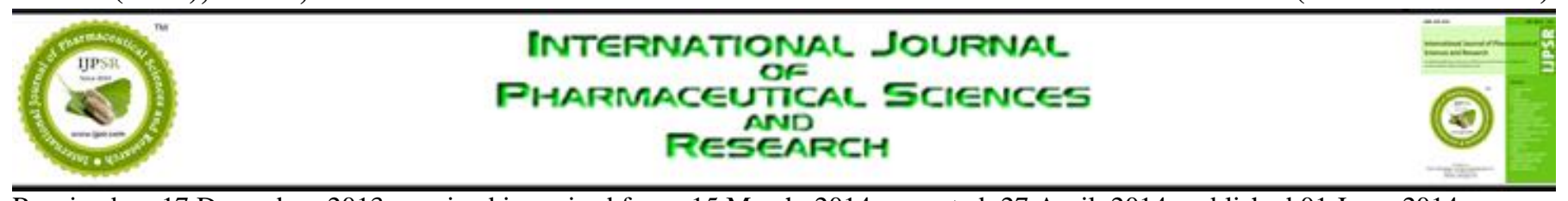

Received on 17 December, 2013; received in revised form, 15 March, 2014; accepted, 27 April, 2014; published 01 June, 2014

\title{
STABILITY-INDICATING SPECTROPHOTOMETRIC METHODS FOR DETERMINATION OF CEFDINIR IN PURE FORM AND PHARMACEUTICAL PREPARATION
}

\section{Khalid A. Attia, Mohammed W. Nassar, Hamed M. Abou-Seada and Mohamed Saleh Emara*}

Department of Pharmaceutical Analytical Chemistry, Faculty of Pharmacy, Al-Azhar University, Cairo, Egypt

Keywords:

Cefdinir,Ratio derivative ,Ratio difference, First derivative, pure form, pharmaceutical preparation

Correspondence to Author:

\section{Mohamed Saleh Emara}

Demonstrator of Analytical

Chemistry, Department of

Pharmaceutical Analytical

Chemistry, Faculty of Pharmacy, Al-

Azhar University, Nasr City, Cairo,

Egypt

E-mail:

mohamed.emara83@yahoo.com

\begin{abstract}
Three Simple, rapid, sensitive, accurate and precise stability-indicating spectrophotometric methods was developed for the determination of cefdinir in bulk powder and in pharmaceutical preparation. Method (A) Ratio derivative method $\left({ }^{1} \mathrm{DD}\right)$; is used for the determination of intact cefdinir in presence of its degradation product at $307 \mathrm{~nm}$ in the range of $2-14 \mu \mathrm{g} \mathrm{ml}^{-1}$ with LOD of $0.049 \mu \mathrm{g} \mathrm{ml}^{-1}$ and LOQ of $0.162 \mu \mathrm{g} \mathrm{ml}^{-1}$. Method (B) Ratio difference method ;is based on measuring the difference in the amplitude of intact cefdinir in presence of its degradation product at two different wavelengths ,this is done at $219 \mathrm{~nm}$ and $250 \mathrm{~nm}$ in the range of $2-14 \mu \mathrm{g} \mathrm{ml}^{-1}$ with LOD of $0.050 \mu \mathrm{g} \mathrm{ml}^{-1}$ and LOQ of $0.165 \mu \mathrm{g} \mathrm{ml}{ }^{-1}$. Method (C) First derivative method $\left({ }^{1} \mathrm{D}\right)$; is used for the determination of intact cefdinir in presence of its degradation product at $304 \mathrm{~nm}$ in the range of $2-14$ $\mu \mathrm{g} \mathrm{ml}^{-1}$ with LOD of $0.034 \mu \mathrm{g} \mathrm{ml}^{-1}$ and LOQ of $0.114 \mu \mathrm{g} \mathrm{ml}^{-1}$. The methods was validated and successfully applied to the determination of cefdinir tablets with an average percent recovery \pm RSD\% of $100.02 \pm 0.643$ for method (A), $100.32 \pm 0.21$ for method (B) and $100.43 \pm 0.86$. The obtained results were statistically compared with those of the reported method by applying t-test and F-test at 95\% confidence level and no significant difference was observed regarding accuracy and precision.
\end{abstract}

INTRODUCTION: Cefdinir (Fig. 1) is ;(6R,7R)7-[2-(2-Amino-4-thiazolyl)glyoxylamido]-8-oxo-3vinyl-5-thia-1-azabicyclo[4.2.0] oct-2-ene-2-carbo xylic acid, 72-(Z)-oxime; 7-\{(2-Amino-1,3-thiazol4-yl)-2-[(Z)-hydroxyimino]acetamido $\}$-3-vinyl cephem-4-carboxylic acid ${ }^{1}$. Cefdinir is the member of what is generally termed the third generation orally active cephalosporin antibiotics ${ }^{2}$.

\begin{tabular}{|l|c|}
\hline QUICK RESPONSE CODE & DOI: \\
\hline
\end{tabular}

Literature survey shows that several spectrophotometric ${ }^{3-6}$ and chromatographic 7-13 methods for determination of cefdinir in pure form, pharmaceutical preparations and/or biological fluids have been reported.<smiles>C=CC1=C(C(=O)O)N2C(=O)[C@@H](NC(=O)/C(=N\O)c3csc(N)n3)[C@H]2SC1</smiles>

FIGURE 1: STRUCTURAL FORMULA OF CEFDINIR 


\section{MATERIALS AND METHODS:}

\section{Apparatus:}

- Shimadzu UV-Vis. 1650 Spectrophotometer (Japan).

- Hot plate (Torrey pines Scientific, USA).

- Jenway, $3510 \mathrm{pH}$ meter (Jenway, USA).

Materials and Reagents: All chemicals and reagents used throughout the work were of analytical grade.

- Cefdinir powder was kindly supplied by Novartis Pharmaceutical Industries Company. (B. NO. A200707).

- Cefdin ${ }^{\circledR} 300 \mathrm{mg}$ capsule. The product of Novartis Pharmaceutical Industries Company. (B. NO.CDRM090002).

- Hydrochloric acid, Sodium hydroxide and Methanol (El-Nasr Co., Egypt).

Standard Solution: A stock solution of cefdinir $(100 \mu \mathrm{g} / \mathrm{ml})$ was prepared by dissolving $10 \mathrm{mg}$ of cefdinir in $50 \mathrm{ml}$ of methanol and complete to 100 $\mathrm{ml}$ with methanol and was further diluted with the same solvent as appropriate. The standard solution was stable for 2 weeks when kept in the refrigerator

Degraded Sample ${ }^{8}$ : Base-induced forced degradation was performed by adding $10 \mathrm{mg}$ of cefdinir to $100 \mathrm{~mL} 0.1 \mathrm{M} \mathrm{NaOH}$ and refluxing at $60^{\circ} \mathrm{C}$ for approximately six hours. The solution was then left to reach ambient temperature, neutralized to $\mathrm{pH} 7$ by addition of $0.1 \mathrm{M} \mathrm{HCl}$, evaporated to dryness, the residue was extracted three times with $25 \mathrm{ml}$ methanol, filtered into $100 \mathrm{ml}$ volumetric flask then the volume was adjusted by the same solvent. The obtained solution was claimed to contain $\left(0.1 \mathrm{mg} \mathrm{ml}^{-1}\right)$.

\section{Procedure:}

\section{Construction of the Calibration Curves (General Procedures):}

Method A: Aliquots equivalent to $(0.02-0.14 \mathrm{mg}$ $\left.\mathrm{ml}^{-1}\right)$ cefdinir and $\left(0.02-0.14 \mathrm{mgml}^{-1}\right)$ cefdinir degradate are accurately transferred from their standard working solutions $\left(20 \mu \mathrm{g} \mathrm{ml}^{-1}\right)$ into two separate series of $10 \mathrm{ml}$ volumetric flasks then completed to volume with methanol. The spectra of the prepared standard solutions are scanned from $200-400 \mathrm{~nm}$ and stored in the computer.

For the determination of cefdinir in presence of its degradation product, the stored spectra of cefdinir are divided by the spectrum of $4 \mu \mathrm{g} \mathrm{ml}^{-1}$ degradate, smoothed with $\Delta \lambda=16 \mathrm{~nm}$ and scaling factor 10 , then the first derivative of the ratio spectra $\left({ }^{1} \mathrm{DD}\right)$ with $\Delta \lambda=4 \mathrm{~nm}$ is obtained. The amplitude of the first derivative trough of (cefdinir / degradate) is measured at $307.0 \mathrm{~nm}$.

A calibration graph relating the trough amplitude at $307.0 \mathrm{~nm}$ to the corresponding concentrations in $\mu \mathrm{g} \mathrm{ml}{ }^{-1}$ of cefdinir is constructed alternatively, the regression equation was derived.

Method B: Aliquots equivalent to $(0.02-0.14 \mathrm{mg})$ were accurately transferred from cefdinir standard stock solution $\left(0.1 \mathrm{mg} \mathrm{ml}^{-1}\right)$ into a series of $10-\mathrm{ml}$ volumetric flasks then completed to volume with methanol. The spectra of the prepared standard solutions are scanned from $200-400 \mathrm{~nm}$ and stored in the computer. For the determination of cefdinir in presence of its degradation product, the stored spectra of cefdinir are divided by the spectrum of $\left(4 \mu \mathrm{g} \mathrm{ml}^{-1}\right)$ of the alkaline degradate. The amplitude difference at 219.0 and $250.0 \mathrm{~nm}(\Delta \mathrm{P} 219.0-$ 250.0) was plotted against the corresponding cefdinir concentration in $\mu \mathrm{g} \mathrm{ml}-1$ and the regression equation was computed.

Method C: Aliquots of standard cefdinir solution in methanol $\left(0.1 \mathrm{mg} \mathrm{ml}^{-1}\right)$ containing $(0.02-0.14)$ $\mathrm{mg}$ of the drug were added to a series of $10 \mathrm{ml}$ volumetric flasks and then diluted to the mark with methanol. First - derivative $\left({ }^{1} \mathrm{D}\right)$ spectra of the drug were recorded against methanol as blank. The height of the trough at $304 \mathrm{~nm}$ was measured in $\mathrm{cm}$ for each drug concentration.

Calibration curve relating troughs height in $\mathrm{cm}$ to drug concentration in $\mu \mathrm{g} \mathrm{ml}^{-1}$ was constructed, the regression equation was derived. 
Analysis of Pharmaceutical Preparation: Ten Cefdin $^{\circledR} 300 \mathrm{mg}$ capsules were accurately weighed and finely powdered, then a quantity equivalent to $10 \mathrm{mg}$ of cefdinir was shaken three times with 25 $\mathrm{ml}$ methanol 15 minutes then filtered into $100 \mathrm{ml}$ volumetric flask and the volume was adjusted to the mark with water to obtain a concentration of $\left(0.1 \mathrm{mg} \mathrm{ml}^{-1}\right)$. The solution was analyzed using the procedure described under method $\mathrm{A}$, method $\mathrm{B}$ and method $\mathrm{C}$.

\section{RESULTS AND DISCUSSION:}

Spectral Characteristics: The zero order $\left(D_{0}\right)$ absorption spectra of cefdinir $\left(10 \mu \mathrm{g} \mathrm{ml}^{-1}\right)$ and its alkaline degradation product $\left(10 \mu \mathrm{g} \mathrm{ml} \mathrm{m}^{-1}\right)$ were recorded against methanol as blank over the range of $200-400 \mathrm{~nm}$ (Figure 2).

For method A: Salinas et al. ${ }^{14}$ designed a spectrophotometric method, which is based on the derivation of the ratio-spectra for resolving binary mixtures. The main advantage of the ratio-spectra derivative spectrophotometry is the chance of doing easy measurements in correspondence of peaks so it permits the use of the wavelength of highest value of analytical signals (a maximum or a minimum) ${ }^{15-17}$. Moreover, the presence of a lot of maxima and minima is another advantage by the fact that these wavelengths give an opportunity for the determination of active compounds in the presence of other compounds and excipients which possibly interferes the assay. In this method the absorption spectrum of the mixture (absorbance at each wavelength) is divided by the absorption spectrum of a standard solution of one of the components, and the first derivative of the ratio spectrum is obtained. The concentration of the other component is then determined from a calibration graph.

The main parameters that affect the shape of the ratio spectra are wavelength, scanning speed, the concentration of the standard solution used as a divisor, the wavelength increment over which the derivative is obtained $(\Delta \lambda)$ and the smoothing function are carefully tested. The ratio spectra presented in Figure (3) and the first derivative of the ratio spectra presented in Figure (4) may provide a good proof for this understanding.
The effect of wavelength scanning speed is studied. It is found that at high speed noisy spectra are obtained while at low scanning speed, the noise is decreased but a longer time is needed for the measurements, so medium scanning speed is chosen to perform measurements. Effect of divisor concentration is also tested, different concentrations of divisor are used $\left(10,8,4 \mu \mathrm{g} \mathrm{ml}^{-1}\right)$ of cefdinir degradate and the divisor concentration $4 \mu \mathrm{g} \mathrm{ml}^{-1}$ of cefdinir degradate is found the best regarding average recovery percent when it is used for the prediction of cefdinir concentrations in bulk powder as well as in laboratory prepared mixtures.

The absorption spectra of cefdinir are divided by the absorption spectrum of $4 \mu \mathrm{g} \mathrm{ml}{ }^{-1}$ cefdinir degradate and smoothed Figure (3) for determination of cefdinir in the presence of its degradate. This gave the best compromise in terms of sensitivity, repeatability and signals to noise ratio. The choice of wavelength for the measurement was carefully studied. The trough amplitude at 307.0 and $230 \mathrm{~nm}$ and peak amplitude at $279 \mathrm{~nm}$ of the first derivative of ratio spectra are then recorded respectively. Good linearity was observed but the recovery percent at $307 \mathrm{~nm}$ was better, which may be attributed to its higher signal to noise ratio.

For method B : Ratio difference ${ }^{18}$ is a new simple, rapid, selective method for the simultaneous determination of components having overlapping spectra in binary mixtures, having the advantages of minimal data processing and wider range of application. The aim of the present work was to develop a new simple, rapid, selective method for simultaneous determination of components having overlapping spectra in a binary mixture. The binary mixture of cefdinir and its alkaline degradation product was chosen as an example for the application of the new ratio difference method.

The absorption spectra of cefdinir and its degradate show a degree of interference as shown in figure (2), that the application of direct spectrophotometry failed to determine cefdinir in the presence of its degradate. Several approaches have been developed to remove the overlapping constant in the ratio spectrum, either using certain order derivative ${ }^{14}$ or through a sophisticated subtraction followed by 
multiplication procedure ${ }^{19}$; the later was capable of determining only the component with the less extended spectrum in the mixture. The ratio difference method is a simple innovative method was capable of determining cefdinir in presence of its alkaline degradate with minimal data processing, high selectivity regardless which component has more extended spectrum.

The method comprises two critical steps ${ }^{18}$, the first is the choice of the divisor, and the selected divisor should compromise between minimal noise and maximum sensitivity. Different concentrations of divisors are used $\left(10,8,6\right.$ and $\left.4 \mu \mathrm{g} \mathrm{ml}^{-1}\right)$ of the degradate and the divisor concentration $4 \mu \mathrm{g} \mathrm{ml}{ }^{-1}$ was found the best regarding average recovery percent when it was used for the prediction of cefdinir concentration in bulk powder as well as in laboratory prepared mixtures.

The second critical step is the choice of the wavelengths at which measurements are recorded. Any two wavelengths can be chosen provided that they exhibit different amplitudes in the ratio spectrum and a good linearity is present at each wavelength individually.

Linear correlation was obtained between the differences in amplitudes at 219.0 and $250.0 \mathrm{~nm}$, against the corresponding concentration of cefdinir. Good linearity is obtained in the concentration range of $2-14 \mu \mathrm{g} \mathrm{ml}^{-1}$ cefdinir.

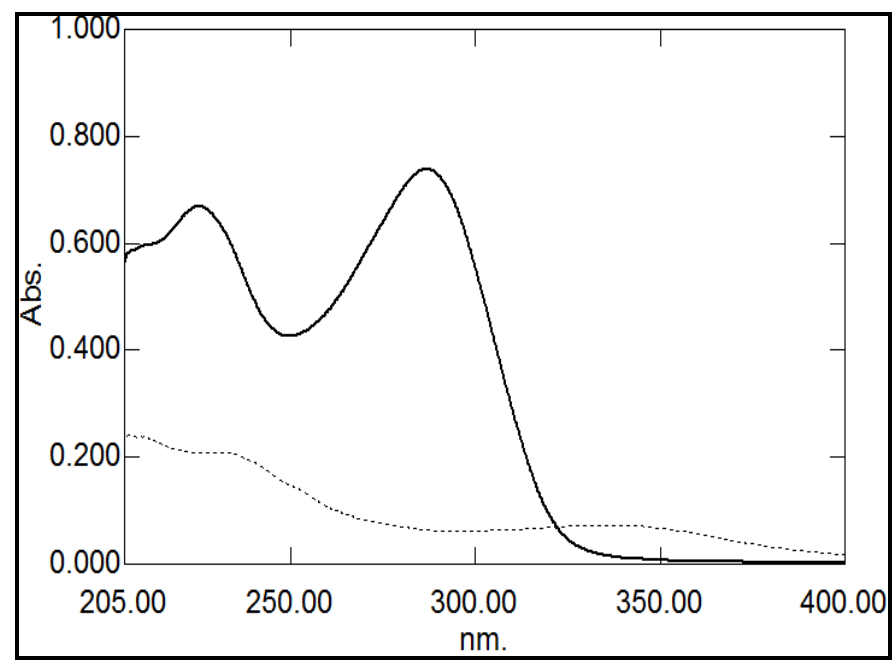

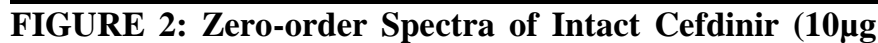
$\left.\mathrm{ml}^{-1}\right)(-)$ and its Degradation Product $\left(10 \mu \mathrm{g} \mathrm{ml}^{-1}\right)(\ldots .$.$) in$ Methanol.

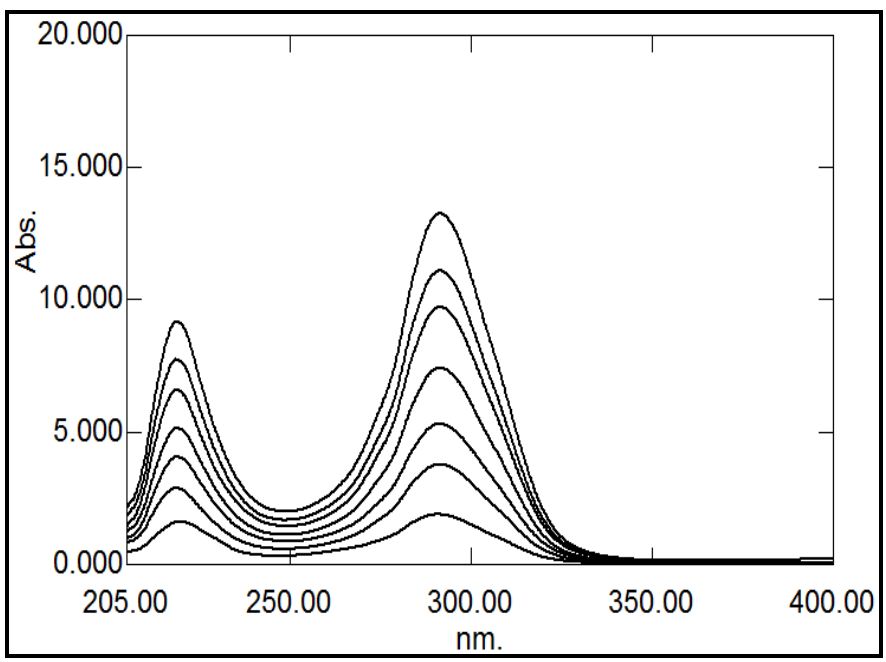

FIGURE 3: Smoothed Ratio Spectra of Cefdinir (2 $\left.14 \mathrm{ugml}^{-1}\right)$ using $\left(4 \mathrm{\mu gml}^{-1}\right)$ Cefdinir Degradate as Divisor and Methanol as Blank.

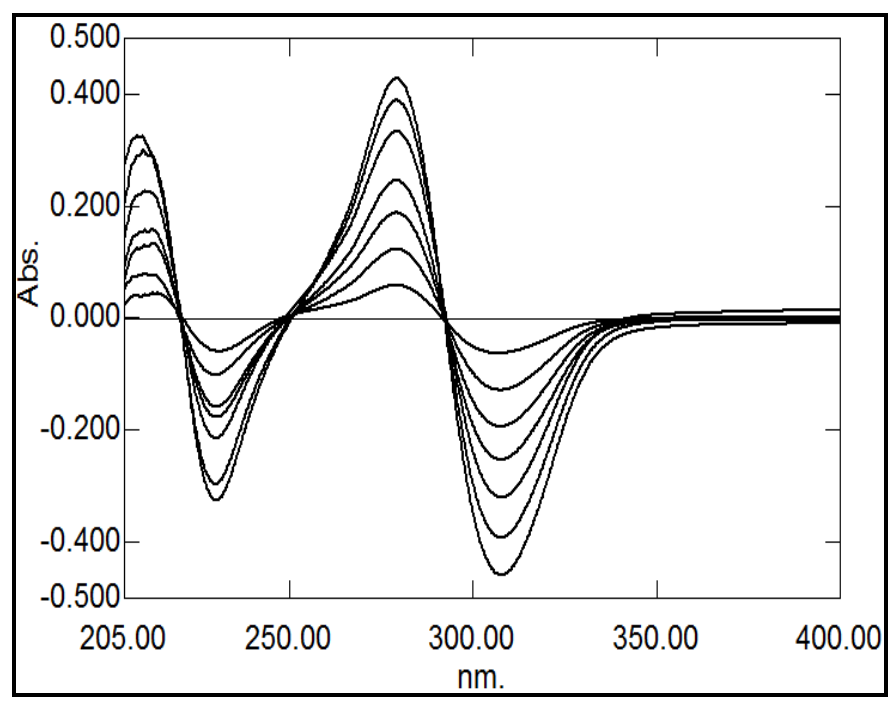

FIGURE 4: First Derivative of Smoothed Ratio Spectra of Cefdinir $\left(2-14 \mathrm{\mu gml}^{-1}\right)$ Using $\left(4 \mathrm{\mu gml}^{-1}\right)$ Cefdinir Degradate as Divisor and Methanol as Blank.

For method C: It is clear from the spectra in figure (2) that, there is a band overlapping between the drug and its degradation product. Such overlapping was eliminated by the first derivative $\left({ }^{1} \mathrm{D}\right)$ scanning of cefdinir and its degradation product in methanol, cefdinir has a trough at 304 $\mathrm{nm}$ which shows no interference from the degradation product.

Thus, it would be possible to adopt the $\left({ }^{1} \mathrm{D}\right)$ spectrophotometry at $304 \mathrm{~nm}$ for direct determination of cefdinir in presence of its degradation product as seen in Figure (5). 


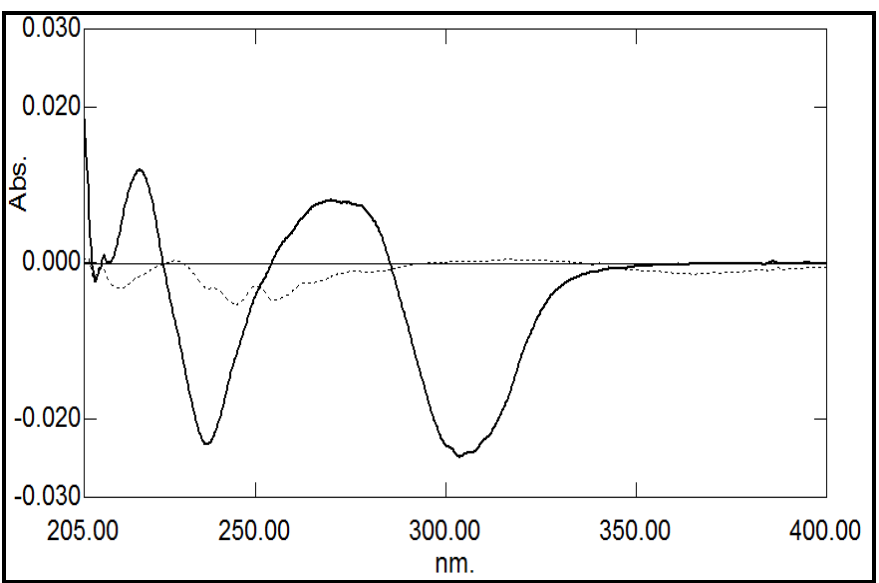

FIGURE 5: First-order Spectra of Intact Cefdinir $(10 \mu \mathrm{g}$ $\left.\mathrm{ml}^{-1}\right)(-)$ and its Degradation Product $\left(10 \mu \mathrm{g} \mathrm{ml}^{-1}\right)(\ldots .$.$) in$ Methanol.

Validation of the Methods:

\section{(i) Linearity:}

Method A: Under the described experimental conditions, the calibration graph for the method was constructed by plotting trough height versus concentration in $\mu \mathrm{g} / \mathrm{ml}$. The regression plot was found to be linear over the range of $2-14 \mu \mathrm{g} / \mathrm{ml}$. The linear regression equation for the graph is:

$\mathrm{P}_{307 \mathrm{~nm}}=0.7446 \mathrm{C}-0.1714$

$r^{2}=0.9999$

Where $\mathrm{C}$ is the concentration of cefdinir in $\mu \mathrm{g} \mathrm{ml}^{-1}$, $\mathrm{P}$ is the trough height of the first derivative of the ratio spectrum curve at $307 \mathrm{~nm}$ and $\mathrm{r}^{2}$ is the correlation coefficient.

Linearity range, regression equation, intercept, slope and correlation coefficient for the calibration data were presented in table 1.

Method B: Linear correlation was obtained between the differences in amplitudes at 219.0 and $250.0 \mathrm{~nm}$, against the corresponding concentration of cefdinir. Good linearity is obtained in the concentration range of $2-14 \mu \mathrm{g} \mathrm{ml} \mathrm{m}^{-1}$. The corresponding regression equation was computed to be:

$\Delta \mathrm{P}_{219.0-250.0}=0.486 \mathrm{C}+0.286$

$\left(r^{2}=0.9998\right)$
Where $\Delta \mathrm{P}$ is the amplitude difference at the selected wavelengths, $\mathrm{C}$ is the concentration in $\mu \mathrm{g}$ $\mathrm{ml}^{-1}$ and $\mathrm{r}^{2}=$ the correlation coefficient.

Linearity range, regression equation, intercept, slope and correlation coefficient for the calibration data were presented in table 1.

Method C: At the described wavelength linear relationship was obtained between the trough in $\mathrm{cm}$ and the cefdinir concentration in the range $(2-14$ $\left.\mu \mathrm{g} \mathrm{ml}{ }^{-1}\right)$. The linear regression equation of the trough was:

$\mathrm{A}_{304}=0.76071 \mathrm{C}+0.05714$

$\left(r^{2}=0.9999\right)$

Where $\mathbf{A}$ is a trough height at 304 in $\mathrm{cm}$ and $\mathbf{C}$ is the drug concentration in $\mu \mathrm{g} \mathrm{ml}^{-1}$.

Linearity range, regression equation, intercept, slope and correlation coefficient for the calibration data were presented in table 1.

(ii) Sensitivity: The limit of detection (LOD) and the limit of quantitation (LOQ) were calculated according to ICH $\mathrm{Q}_{2}$ Recommendation ${ }^{20}$ from the following equations:

$\mathrm{LOD}=3.3 \mathrm{~S}_{\mathrm{a}} /$ slope

$\mathrm{LOQ}=10 \mathrm{~S}_{\mathrm{a}} /$ slope

Where $S_{a}$ is the standard deviation of the intercept of regression line.

LOD was found to be $0.049,0.05$ and $0.034 \mu \mathrm{g} / \mathrm{ml}$, while LOQ was found to be $0.162,0.165$ and 0.114 $\mu \mathrm{g} / \mathrm{ml}$ for method $\mathrm{A}, \mathrm{B}$ and $\mathrm{C}$ respectively. The small values of LOD and LOQ indicate good sensitivity.

(iii)Accuracy and Precision: Three replicate determinations of three different concentrations of cefdinir in pure form within linearity range were performed in the same day (intra-day) and in three successive days (inter-day). Accuracy as recovery percent $(\mathrm{R} \%)$ and precision as percentage relative standard deviation $(\mathrm{RSD} \%)$ were 
calculated and results are listed in table 2. The small values of RSD\% indicate high precision of the method. Moreover, the good $\mathrm{R} \%$ confirms excellent accuracy.

Specificity: The specificity of the proposed methods was assured by applying the laboratory prepared mixtures of the intact drug together with its degradation product.

The proposed method was adopted for the specific determination of intact cefdinir in presence of up to $57.14 \%$ of its corresponding degradates for the three methods.

TABLE 1: SPECTRAL DATA FOR DETERMINATION OF CEFDINIR BY THE PROPOSED METHODS:

\begin{tabular}{cccc}
\hline Parameters & Ratio derivative & Ratio difference & First derivative \\
\hline$\lambda_{\max }(\mathrm{nm})$ & 307 & $219.0-250.0$ & 304 \\
Linearity range $\left(\mu \mathrm{gml}^{-1}\right)$ & $2-14$ & $2-14$ & $2-14$ \\
LOD $\left(\mu \mathrm{gml}^{-1}\right)$ & 0.049 & 0.05 & 0.034 \\
LOQ $\left(\mu \mathrm{gml}^{-1}\right)$ & 0.162 & 0.165 & 0.114 \\
Regression equation $^{*}$ & & & \\
Slope $(b)$ & 0.745 & 0.486 & 0.76 \\
Intercept $(a)$ & 0.171 & 0.286 & 0.057 \\
Correlation Coefficient $\left(r^{2}\right)$ & 0.9999 & 0.9998 & 0.9999 \\
\hline
\end{tabular}

TABLE (2): INTRADAY AND INTERDAYS ACCURACY AND PRECISION FOR THE DETERMINATION OF CEFDINIR BY THE PROPOSED METHODS:

\begin{tabular}{|c|c|c|c|c|c|c|c|}
\hline & \multirow[b]{2}{*}{$\begin{array}{c}\text { Conc. } \\
\mu^{-1} \mathrm{ml}^{-1}\end{array}$} & \multicolumn{3}{|c|}{ Intra-day } & \multicolumn{3}{|c|}{ Inter-day } \\
\hline & & $\begin{array}{c}\text { Found } \\
\text { Conc. } \pm \text { SD } \\
\end{array}$ & $\begin{array}{c}\text { Accuracy } \\
(\mathbf{R} \%)\end{array}$ & $\begin{array}{c}\text { Precision } \\
(\text { RSD\% })\end{array}$ & $\begin{array}{c}\text { Found } \\
\text { Conc. } \pm \text { SD } \\
\end{array}$ & $\begin{array}{c}\text { Accuracy } \\
(\mathbf{R} \%)\end{array}$ & $\begin{array}{c}\text { Precision } \\
(\text { RSD\%) }\end{array}$ \\
\hline \multirow{3}{*}{ 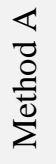 } & 6 & $5.99 \pm 0.028$ & 99.85 & 0.645 & $6.037 \pm 0.025$ & 100.61 & 0.58 \\
\hline & 8 & $8.059 \pm 0.039$ & 100.47 & 0.684 & $8.02 \pm 0.017$ & 100.25 & 0.285 \\
\hline & 10 & $10.08 \pm 0.064$ & 100.838 & 0.873 & $10.11 \pm 0.085$ & 101.129 & 1.154 \\
\hline \multirow{3}{*}{ 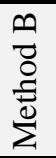 } & 6 & $5.907 \pm 0.03$ & 98.46 & 0.969 & $5.97 \pm 0.03$ & 99.44 & 0.95 \\
\hline & 8 & $7.876 \pm 0.01$ & 98.45 & 0.243 & $7.87 \pm 0.034$ & 98.43 & 0.84 \\
\hline & 10 & $10.018 \pm 0.05$ & 100.18 & 0.974 & $10.107 \pm 0.049$ & 101.07 & 0.94 \\
\hline \multirow{3}{*}{$\begin{array}{l}u \\
0 \\
0 \\
0 \\
\sum \\
\sum\end{array}$} & 6 & $5.995 \pm 0.032$ & 99.92 & 0.696 & $5.99 \pm 0.046$ & 99.84 & 1.004 \\
\hline & 8 & $7.96 \pm 0.01$ & 99.52 & 0.173 & $7.94 \pm 0.038$ & 99.194 & 0.631 \\
\hline & 10 & $10.04 \pm 0.033$ & 100.399 & 0.428 & $10.032 \pm 0.052$ & 100.32 & 0.672 \\
\hline
\end{tabular}


TABLE 3: DETERMINATION OF CEFDINIR IN MIXTURES WITH ITS DEGRADATION PRODUCT BY THE PROPOSED METHODS:

\begin{tabular}{|c|c|c|c|c|c|}
\hline \multirow{2}{*}{$\begin{array}{c}\text { Intact } \\
\left(\mu \mathrm{g} \mathrm{ml}^{-1}\right)\end{array}$} & \multirow{2}{*}{$\begin{array}{c}\text { Degradate } \\
\left(\mu \mathrm{g} \mathrm{ml}^{-1}\right)\end{array}$} & \multirow{2}{*}{$\underset{\%}{\text { Degradate }}$} & \multicolumn{3}{|c|}{ Recovery\% of Intact } \\
\hline & & & Ratio derivative & Ratio difference & First Derivative \\
\hline 12 & 2 & 14.29 & 99.28 & 100.09 & 101.25 \\
\hline 10 & 4 & 28.57 & 101.01 & 101.4 & 100.47 \\
\hline 8 & 6 & 42.86 & 99.4 & 99.25 & 99.3 \\
\hline 6 & 8 & 57.14 & 98.96 & 100.99 & 99.53 \\
\hline 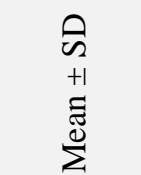 & & & $99.66 \pm 0.916$ & $100.43 \pm 0.959$ & $100.14+0.899$ \\
\hline
\end{tabular}

TABLE 4: DETERMINATION OF CEFDINIR IN CEFDIN ${ }^{\circledR}$ CAPSULES $(300 \mathrm{mg})$ BY THE PROPOSED AND REPORTED METHODS

\begin{tabular}{ccccc}
\hline \multirow{2}{*}{ Parameters } & \multicolumn{3}{c}{ Proposed Methods } & \multirow{2}{*}{${\text { Reported } \text { method }^{4}}^{\mathbf{4}}$} \\
\cline { 2 - 4 } & Ratio Derivative & Ratio Difference & First derivative & 5 \\
$\mathbf{N}^{*}$ & 7 & 7 & 7 & 99.86 \\
$\mathbf{X}^{-}$ & 100.02 & 100.32 & 100.43 & 0.71 \\
$\mathbf{S D}$ & 0.64 & 0.21 & 0.864 & 0.71 \\
$\mathbf{R S D \%}$ & 0.64 & 0.21 & 0.86 & \\
\cline { 2 - 5 } $\mathbf{t}^{* *}$ & 0.401 & 1.405 & 1.251 & \\
& $(1.8125)$ & $(1.8125)$ & $(1.5125)$ & \\
$\mathbf{F}^{* *}$ & 1.23 & 0.087 & 0.675 & \\
\hline
\end{tabular}

* No. of experimental. ** The values in the parenthesis are tabulated values of $\mathrm{t}$ and $\mathrm{F}$ at $(\mathrm{p}=0.05)$.

CONCLUSION: The proposed method is simple, rapid and inexpensive. So, it is good alternative to the other few reported methods and to the high cost HPLC methods.

ACKNOWLEDGMENT: The authors thank Department of Pharmaceutical Analytical Chemistry, Faculty of Pharmacy, Al-Azhar University for supporting this work.

\section{REFERENCES:}

1. The Merck Index, 15th edition, Whitehouse Station, NJ: Merk \& co., Inc., Electronic version 2013.

2. Sweetman S (Ed), Martindale: The complete drug reference. London: Pharmaceutical Press. Electronic version, Edition 2009.

3. Gouda AA, Hashem H, Hassan W; Drug Test Anal., 2012; 4(12):991-1000.

4. Rao Narala Srinivasa; Saraswathi K; Asian Journal of Research in Chemistry; 2011; 4(2), 270.

5. Babita K, Singhe Dilip V, Parwate ; Quim. Nova, 2010; 33(7): 1471-1475.
6. B. S. Virupaxappa, K. H. Shivaprasad. International Journal of Pharmaceutical Research 2013; 5(4).

7. Srinivasa Rao Narala, K. Saraswathi, J. Pharm. Sci. \& Res.; 2011; 3(1): 1002-1004.

8. Purnima Hamrapurkar, Priti Patil, Mitesh Phale, Mital Gandhi, and Sandeep Pawar; Pharm. Methods, Jan-Mar; 2011; 2(1): 15-20.

9. Golam Mortuza Shahed, Md Ashik Ullah, Al Abdullah Al Abdullah, Maizbha Uddin Ahmed, Mohammad Safiqul Islam, Zebun Nahar Abul Hasnat; Dhaka University, Journal of Pharmaceutical Sciences 2011; 10(2) .

10. U.C. Mashelkar, Sanjay D. Renapurkar; International Journal of ChemTech Research 0974-4290; 2010; 2 (1): 114-121.

11. Khan A, Iqbal Z, Khan MI, Javed K, Khan A, Ahmad L, Shah Y, Nasir F. ; J Chromatogr B Analyt Technol Biomed Life Sci.; 2011; 879(24): 2423-9.

12. Hisham Hashem, Ayman A. Gouda and Wafaa Hassan ; Journal of Liquid Chromatography \& Related Technologies, 2012, 35:1638-1648.

13. A.M.Kessiba, M.Abd El Kawy, M.A.Hegazy, A.E.El Gindy; Indian Journal. Analytical Chemistry, 2012, 11 (2).

14. Salinas F; Nevado J and Mansilla A; Talanta, 1990; 37(3): 347 - 351 . 
15. El-Gindy A; Ashour A; Abdel-Fattah L and Shabana M; J. Pharma. Biomed. Anal., 2001, 24 (4): $527-534$.

16. Lemus J and Arroyo P, J. Analytica Chimica Acta, 2001; 437(2): 247- 257.

17. Tena RC; Delgado M A; Sanchez M J and Montelongo F G; Talanta, 1997; 44(4): 673-683.

18. Elzanfaly ES; Saad AS and Abd-Elaleem AE; Saudi Pharm. J.; 2012; 20: 249 - 253.
19. El-Bardicy M G; Lotfy H M; El-Sayed M A and El-Tarras M F; J. AOAC Int.; 2008; 91(2): 299 -310 .

20. ICH Q2 (R1), Validation of analytical procedure, Text and methodology, Geneva, International conference on Harmonization, 2005.

\section{How to cite this article:}

Attia KA, Nassar MW, Abou-Seada HM and Emara MS: Stability-indicating spectrophotometric methods for determination of Cefdinir in pure form and pharmaceutical preparation. Int $\mathbf{J}$ Pharm Sci Res 2014; 5(6): 2230-37.doi: 10.13040/IJPSR.0975-8232.5(6).2230-37

All $\odot 2013$ are reserved by International Journal of Pharmaceutical Sciences and Research. This Journal licensed under a Creative Commons Attribution-NonCommercial-ShareAlike 3.0 Unported License.

This article can be downloaded to ANDROID OS based mobile. Scan QR Code using Code/Bar Scanner from your mobile. (Scanners are available on Google Playstore) 